As expected, procedure duration was longer on training procedures; 30.6 (12.3) vs. 46.6 (14.2) minutes, $p<0.001$.

Conclusion In conclusion, colonoscopy is delivered at a similar high quality when performed by trainees compared with trained endoscopists. Although trainees took longer, caecal intubation rates and polyp detection were similar to those of trained endoscopists. Interestingly, patient discomfort reported by endocopist was lower during training colonoscopies and could possibly relate to longer procedure time. These conclusions will be used for patient information and monitored as quality assurance.

Disclosure of Interest None Declared

\section{PTU-033 META-ANALYSIS OF FLEXIBLE SPECTRAL IMAGING COLOUR ENHANCEMENT (FICE) IN DETECTION AND CHARACTERIZATION OF COLORECTAL POLYPS}

doi:10.1136/gutjnl-2013-304907.125

1."C Raychaudhuri, 'N Mohammed, 'V Subramanian. 'Department of Gastroenterology and Leeds Institute of Molecular Medicine, St James University Hospital, Leeds, UK

Introduction Several endoscopic innovations have been developed recently to improve detection and characterization of colorectal polyps. Flexible spectral imaging colour enhancement (FICE) is a form of image enhanced endoscopy which enhances the visualisation of mucosal structures and microcirculation by the selection of spectral transmission with a dedicated wavelength.

Methods Various electronic databases were searched for articles reporting on detection and characterization of colonic polyps comparing standard while light endoscopy and FICE. The pooled mean differences in total numbers of polyps, adenomatous polyps, flat adenomas, and hyperplastic polyps detected was calculated. Additionally, pooled sensitivity, specificity, positive and negative likelihood ratio, diagnostic odds ratio and pooled area under the receiver operating curve was calculated. A fixed effects model was used unless there was significant heterogeneity. Publication bias was assessed using Funnel plots and Egger's test and heterogeneity was assessed using Cochran's $\mathrm{Q}$ and the $I^{2}$ test.

Results 5 studies/2150 patients and 11 studies/2425 patients were included in the analysis for detection of polyps and polyp characterization respectively. There were no differences between FICE and standard colonoscopy for the detection of all polyps, adenomatous

Abstract PTU-033 Table 1 Detection of polyps with FICE

\begin{tabular}{lll}
\hline Variable tested & Pooled difference in means (95\% CI) & p values \\
\hline All polyps & $0.132(-0.064$ to 0.328$)$ & 0.188 \\
All adenomas & $0.033(-0.056$ to 0.122$)$ & 0.468 \\
Flat adenomas & $0.077(-0.099$ to 0.254$)$ & 0.389 \\
Hyperplastic polyps & $0.104(-0.072$ to 0.280$)$ & 0.248 \\
\hline
\end{tabular}

polyps, flat adenoma or hyperplastic polyps (Table 1). Table 2 lists the pooled diagnostic accuracy parameters for FICE. A random effects model was used in both because there was heterogeneity between the studies.

Conclusion FICE does not seem to improve the detection rate of adenomatous polyps during screening colonoscopy. These results may partially be due to the small number of studies done so far using FICE. The pooled sensitivity and specificity of FICE does not meet the currently accepted criteria of the ASGE PIVI committee for use in routine clinical practise.

Disclosure of Interest None Declared

\section{PTU-034 ENDOSCOPIC RETROGRADE CHOLAGIOPANCREATOGRAPHY IN THE ELDERLY: PROCEDURES AND COMPLICATIONS AT A DISTRICT GENERAL HOSPITAL}

doi:10.1136/gutjnl-2013-304907.126

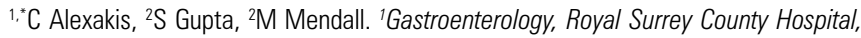
Guildford; '² Gastroenterology, Croydon University Hospital, London, UK

Introduction Endoscopic retrograde cholangiopancreatography (ERCP) has previously been demonstrated to be a safe and effective procedure in the elderly. The aim of this study was to assess whether similar safety data for this procedure was reproducible at a district general hospital.

Methods All patients undergoing first time ERCP between January 2007 and December 2008 were included. Data collection was partially incomplete as some procedure records were missing. Study variables included age, sex, indications, complications, and in-hospital mortality. Statistical analysis was performed to address differences in complication rates between the elderly ( $>80$ years, Group A) and non-elderly ( $<80$ years, Group B) patients.

Results Data was available for 197 ERCPs. Mean age at ERCP was 65.77 years. There were 47 (23.9\%) ERCPs in Group A (mean age 86 years, range $81-97$ ), and 150 (76.1\%) in Group B (mean age 57 years, range 18-80). The indications and complications for procedures are demonstrated in Table 1.

There were a total of 28 complications, $8(17.0 \%)$ in Group A, and $20(13.3 \%)$ in Group B. There was no significant difference in total complication rates between the 2 groups (Fisher's exact 2 -tailed test, $p=0.63)$. Similarly, no significant differences were identified in specific complications between Group A and B (2-tailed Fisher's exact test): bleeding $(p=1.00)$, pancreatitis $(p=0.63)$, biliary sepsis $(p=1.00)$, perforation $(p=1.00)$, others $(p=0.20)$. There were no in-hospital deaths directly related to ERCP in either age group $(p=1)$

Conclusion There was no increase in procedural complication rates or mortality in elderly patients undergoing ERCP in our study population. Our data adds weight to the growing evidence that ERCP is a safe and well tolerated procedure in the elderly.

Disclosure of Interest None Declared

Abstract PTU-033 Table 2 Characterization of polyps with FICE

\begin{tabular}{|c|c|c|c|c|c|c|}
\hline Variable tested & $\begin{array}{l}\text { Pooled sensitivity } \\
\text { (95\% Cl) }\end{array}$ & $\begin{array}{l}\text { Pooled specificity } \\
(95 \% \mathrm{CI})\end{array}$ & $\begin{array}{l}\text { Pooled positive } \\
\text { likelihood ratio } \\
(95 \% \mathrm{CI})\end{array}$ & $\begin{array}{l}\text { Pooled negative likelihood ratio } \\
(95 \% \text { Cl) }\end{array}$ & $\begin{array}{l}\text { Pooled diagnostic Odds ratio } \\
(95 \% \mathrm{Cl})\end{array}$ & $\begin{array}{l}\text { Pooled area under the receiver } \\
\text { operating curve } \\
(95 \% \mathrm{Cl})\end{array}$ \\
\hline Polyps $<5 \mathrm{~mm}$ & $\begin{array}{l}85.9 \% \\
(81.1 \text { to } 89.9)\end{array}$ & $\begin{array}{l}85.5 \% \\
(79.3 \text { to } 90.4)\end{array}$ & $\begin{array}{l}5.4 \\
(3.75 \text { to } 7.77)\end{array}$ & $\begin{array}{l}0.17 \\
(0.113 \text { to } 0.255)\end{array}$ & $\begin{array}{l}32.81 \\
(16.74 \text { to } 64.33)\end{array}$ & $0.914+/-0.017$ \\
\hline Polyps $<10 \mathrm{~mm}$ & $\begin{array}{l}91.3 \% \\
(88.4 \text { to } 93.7)\end{array}$ & $\begin{array}{l}74.7 \% \\
(68.5 \text { to } 80.2)\end{array}$ & $\begin{array}{l}3.86 \\
(2.37 \text { to } 6.30)\end{array}$ & $\begin{array}{l}0.115 \\
(0.07 \text { to } 0.19)\end{array}$ & $\begin{array}{l}37.08 \\
(16.01 \text { to } 85.85)\end{array}$ & $0.902+/-0.08$ \\
\hline All Polyps & $\begin{array}{l}90.4 \% \\
\text { (88.3 to } 92.2 \text { ) }\end{array}$ & $\begin{array}{l}86.9 \% \\
\text { (83.8 to } 89.5)\end{array}$ & $\begin{array}{l}5.96 \\
\text { (2.32 to } 15.32 \text { ) }\end{array}$ & $\begin{array}{l}0.135 \\
(0.08 \text { to } 0.225)\end{array}$ & $\begin{array}{l}45.56 \\
(15.13 \text { to } 137.15)\end{array}$ & $0.945+/-0.025$ \\
\hline
\end{tabular}

